\title{
Future of science to foster being
}

\author{
F. M. Riegler
}

Published online: 7 February 2014

(C) Springer-Verlag Wien 2014

\section{Dear Readers,}

While the eastern part of West Asia shakes the soul of the people in various regions and tries a revolution, within the center of the continent, politics try to find a solution for Syria, again and again, the ancient time-rooted blood-suckling soil tries for another way of peace.

The world is in a good shape if we think, as long as we reason, the world gets to form a dangerous shape if we stop to think. Permanent does not mean forever. How can we assess, when academics stop to think? We stop to think when we calculate, operate with a computer, apply a formula, press data through the pumps of a logistic regression number coiling valve to model the organism along our ideas and to justify our existence of being a scientist. I agree: this is a dilemma.

Due to the fact that academic science has to operate with controls, stocks, crowds of humbling numbers, science does not allow to think. Studies are a collection of characteristics according to the order of our imagination, which in fact means to press it into the mode of school medicine; thus it has to serve the model of school medicine and thus serves to justify the model of school medicine and thus, at the end, inhibits progress. We are talking about the progress defined by the search for the essence, the ground of our perceptions. However, there is only one way, one single path to approach the ground, the essence of things, facts, perceptions, and this is to think, reason. But we do not have to think about things, we have to directly think the things. And here love comes into play, love for reasoning, far off the road directed and pushed by the numbers of profit, greed, envy and hate.

\section{F. M. Riegler $(\square)$}

Manometry Lab \& Department of Surgery,

Medical University Vienna, Waehringer Guertel 18-20, 1090 Vienna, Austria

e-mail: franz.riegler@meduniwien.ac.at
The essence is always neutral, outbalanced and named the "is", the being, the very soul of it all. Here we face the other extreme of the spectrum, the other side of the coin: open mindedly watch and see, think and reason. Both extremes are necessary, as both gave birth to all, made winners and losers, heads and slaves, god and man, light and darkness, at the very end of it all.

Remains to be questioned, what means to think and reason? What means to question and reply?

Thinking means to translate the perception-modulating state of mood into the language of the spoken sign, the word. It offers the only way to bring the essence of a perception into our existence. Furthermore, many, most or all perceptions can be drawn back towards a common ground: being. Going in line with the ancient Greek brilliant rock 'n' roll thinkers Anaximander, Parmenides, and Heraclitus, all manifest as perceptions that we perceive and those we cannot perceive. Well-tuned relaxed opens the mouth of a god to shine, and nothing else. Read the light, as you will. Be a star, as you face. The beauty of the sea gloriously waters the golden brown sands of a beach (Fig. 1). Running out from the hills rides the land into the sea and pulsatile kisses the waves at the dancing shore line mingling and tackling to the music of harmonies bending it all to the very foundation of pride: steam in astonishment. Past reminds the future as the will of the last god comes up to smile the very good bye before deciding to vanish into the continuous clarity of remembrance: history started with the last days of the gods, facts replace the once-upon-a-time emotions. We gave it away? Shall we rethink to get it back? Childhood instead of lion clubs? Beef eaters instead of sweet sucker diabetics? Academics watch out. Babylon fell not the towers.

Science takes apart what belongs together, cuts water into segments, picks out what serves to be seen as one. The drop tells the story of the ocean. The blue sky hides the glory of the stars. The cloud flies the minds of the oceans. The stone rivers the origin of the existence. The 


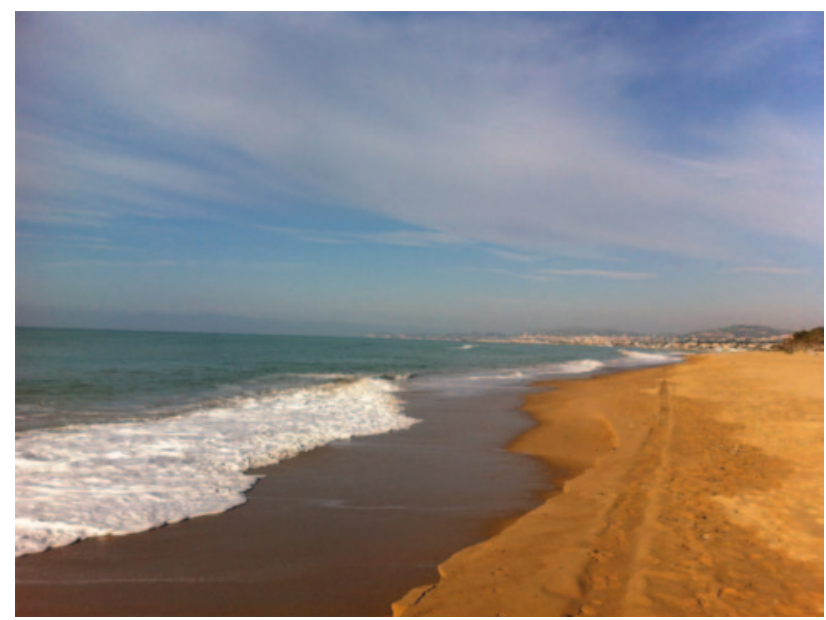

Fig. 1 The run-outs of the open-minded ocean meet the downhill-racing sands of the land to orchestrate the beauty of the beach. The image mirrors the idea of the author, as outlined in the text. (Obtained using iPhone in San Leone, Sicily, December 2013)

universe is the question mark for the deepest state of mood: thankfulness, and the recognition that it is all borrowed for its specific time. And here the waters clear the ground, vision comes into play to the essence: no fish without water, no water without rain, no ocean without wells and no circuits without rolling. Most importantly, science knows one single sign that decodes the circuit of life, the stream of soul, the breath of the mood; this is the timeless rolling number of $\pi$. The $\pi$ is the beth, the house-keeping preacher unfolding the secrets of the lotus flower put into stone since thousands of years in the form of pyramids, temples, churches, castles and even in the form of the measures of computers and generators of our modern technology. $\pi$ Runs the world, but we who are stunned are not any more aware of its very meaning. The cosmic $\pi$ mirrors it all, the stars, worlds and lights, $\pi$ the apeiron, physis, being, athman, brahman, soul. And most importantly, us, this is YOU.

It seems time is ready for us to take it for granted and look out for the signs we produce. Let us start to think and go for the questions: what is being, existence? What are we? What means time, space and responsibility, we have for our patients and the world? Let our systems and chiefs and bosses accept: we need time to reason, otherwise our science and works continue to become a war field of meaningless numbers and data to serve the models of misconception. And this would be the basis of our art to treat patients? Allow questions without answers. Let us close the gap to join into the spectrum for the revival of the open-minded approach. Mentality counts and may fill time, being and space, again. Stay well tuned within the essence.

Sincerely, Martin Riegler

\section{Conflict of interest}

The author declares no conflict of interest. 